\title{
Multimodal Tundang Mayang Pusaka Malay Tradition West Kalimantan
}

\author{
Adisti Primi Wulan ${ }^{1,2}$, Maryaeni ${ }^{3}$, Djoko Saryono ${ }^{4}$ and Taufik Dermawan ${ }^{5}$ \\ 1,3,4,5 Doctor Program of Department of Indonesian Language Education, Postgraduate \\ Program, Universitas Malang, Malang, Indonesia \\ ${ }^{2}$ Department of Language and Literature Education, IKIP PGRI Pontianak, Indonesia
}

adistiprimiwulan@ikippgriptk.com

\begin{abstract}
This study describes the multimodal Tundang Mayang Pusaka Melayu as one of the cultural roots of West Kalimantan. The multimodal that observed in this study is the interaction of language and meaning for Tundang development. Using an ethnopuitic approach, Haymes and Tedlok (1983) Ethnopuitic studies contain two main elements, namely the language-literary element (universality of the line model Haymes or the universality of poetics features) and sound elements (the art or aesthetics of sounding the narratives texts Tedlock's model) and the combination of the multimodal approach, Anstey and Bull (2010), the analysis was carried out to obtain linguistic, visual, audio, gestural and spatial elements from Tundang.
\end{abstract}

Keywords: Multimodal; Ethmopuitika; Tundang

\section{INTRODUCTION}

The modernization of literary works reflects the culture of a particular society in maintaining its valuable property which in some ways reflects the ideology that operates in that society. Likewise with Tundang, as one of the culture of West Kalimantan, Tundang to be preserved because it contains values that are able to build and control people's behavior. Tundang Mayang Pusaka show contains not only functional performances, but also practical functions designed by art performers that reflect certain meanings, namely the success of Tundang shows that are able to penetrate across generations and socially.

Tundang oral literary works that combine two oral literature namely poem and poet, traditional ethnic Malay literary works which must be preserved as local cultural wealth, and preserved so as not to become extinct. Tundang (pantun berdendang) This local literary work becomes a characteristic of identity, the collective property of the owner's community, and inherited from generation to generation orally [1]. Therefore, classified as oral literature 
(literature orally or unwritten literature), also called unwritten literature classified as oral folklore, is fundamental, is valued, transmitted from generation to generation consciously in different versions, and accompanied by gestures or tools reminder helpers [2] [3] [4].

According to Kress and van Leeuwen's [5] viewsstates that the development of literature has been influenced by the three important factors during the 20th century. First, in Western culture a variety of cultural arts activities both scientific and popular are shifted from economics to multimodal and multimedia. These cultural arts activities have used media / tools to cross the boundary between various arts, designs, and disciplines. Second, modern semiotics are inspired to cross the boundaries outside of their studies. The main stream of semiotics seeks to develop a semi-theoretical framework that applies to all modes, from costumes in folk poetry to costumes worn by modern theater players. Third, the study of multimodal discourse is the development of technology, especially computer technology, to record, replay, and analyze text and multimodal phenomena

Multimodal comes from the word multimodality which means a term used to refer to the way people communicate using different modes at the same time [6]. Multimodal can also be said as a "technical term that aims to show that the meaning we have done so far uses a variety of semiotics" [7].

While Chen [8] interpreted multimodality as "understanding how semiotic sources of verbal and visual can be used to realize the types and levels of dialogic engangement, dialogic involvement in a textbook".

The relationship between multimodal and Tundang in this article is the magnitude of the first and third factors in multimodal development. With the rapid development of media of communication and informatics, Tundang also developed. At the moment the Tundang is also published through video uploading as a form of promotion of regional culture.

\section{METHOD}

The object in this study is Tundang, tundang is an old literary work that still has a close relationship with old poetry, namely pantun which belongs to multimodal texts. All interactions that combine two tools can give a combination to the language namely verbal and nonverbal are called multimodal [9]. Anstey and Bull [10] argue that a text can be defined as multimodal when combining two or more semiotic systems. They took the example of an audio-visual advertisement of food products, then analyzed with multimodal based on the semiotic system.

In the analysis of linguistic elements, a metafunctional analysis of the Halliday language [11] was conducted. The analysis used is only at the ideational level of the experiential function. The analysis is not continued in the realm between persona and also textual because the research objectives have been reached at the ideational level. In this area, the linguistic elements found in the Indonesian version of Indomie advertisements have been grouped based on their functions in the application to daily life. In this function you have seen a place, time, process and the cast. Therefore analysis is only up to ideational meaning. 


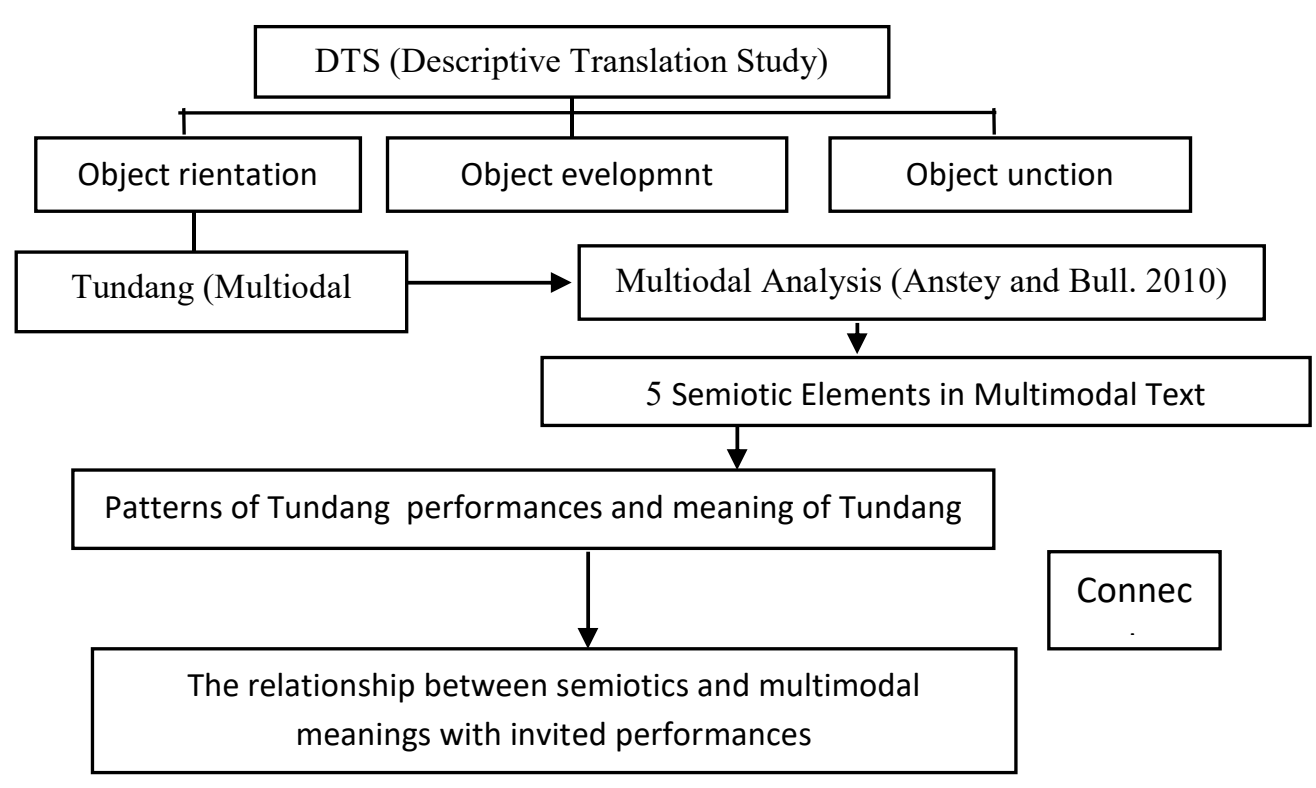

Image 2.1 Conceptual Framework

\section{RESULT AND DISCUSSION}

Here, the results and findings of the study will be explained. The analysis step described above can be applied as follows.

\subsection{Linguistics on Tundang}

Tundang or rhyme is included in old poetry literature. The performances that are dubbed with the music makes Tundang different from the old poetry and has a high attraction for various generations. Not different with the characteristic of pantun which is bound, Tundang texts are also bound by various linguistic rules. $a-b-a-b$ rhyme, each couplet onsists of 4 lines, consisting of sampiran and contents.

The language used in Tundang is speech that is imaginary, concrete, and figurative. Image is a word or arrangement of words that can express sensory experiences, such as vision, hearing and feeling. Concrete words are words that can be captured by the senses so that images appear. These words are related to figures of speech or symbols. Figurative language is related to rhyme, rhythm, and mentrum. Rima is the sound equivalent to poetry in the beginning, middle, and end of the poem line.

\subsection{Visual on Tundang}

Based on some Tundang video that are spread on the internet, for example on youtube.com page, the shooting process during the performance is not maximal. This is evidenced by the video quality which is still $360 \mathrm{~kb}$ so that it is still far from the normal video standard of at least between $480 \mathrm{~kb}, 720 \mathrm{~kb}$ or $1080 \mathrm{~kb}$ which is equivalent to HD (high quality). Uploaded videos of Tundang shows on the youtube page indirectly contributed to the promotion of Tundang to the 
people of West Kalimantan in particular, and the wider community both foreign and domestic in general.

By maximizing uploading the videos of Tundang shows, Tundang will be increasinglyrecognized and conservation efforts can go well with the many responses and support from peoples who watched the Tundang show.

\subsection{Audio on Tundang}

As a video supporter, audio plays an important role. With the characteristic of Tundang which deliver pantun by singing, audio is the main element in the show. With a large audience capacity, the use of clip on for actor is highly recommended to reach all audiences and if recorded, the voices of the actors are well recorded.

\subsection{Gestural on Tundang}

During the Tundang performance, because pantun were delivered by singing, it required the accuracy of the to do gestures in accordance with the meaning of the pantun and the singing of the song. By paying attention to the Petundang's gestures, the audience will be interested because the show is not only enjoyed by hearing, but it's also supported with visuals by showing the gesture of the Petundang so the performance is not monotonous.

\subsection{Spatial on Tundang}

Performances that are supported by visual, audio, and gestural will be more complete if supported

by spatial or supporting aspects of the performances of Tundang for example, stage layout and stage decoration. Mastery of the stage also needs to be utilized by the petundang.

With the rapid development of technology, Tundang performances with modern packaging are highly recommended without reducing the values that contained in them.

\section{CONCLUSION}

This article explained how Tundang can survive in the era of globalisation and modernization. With increasing the quality of the Tundang performance and support from peoples, Tundang will long-lasting and can enjoy by generation to generation without reducing or deleting the values that contained in Tundang.

\section{ACKNOWLEDGMENT}

The researcher thanked LPDP BUDIDN as the research sponsor. Further thanks go to Rector of IKIP PGRI Pontianak, west Borneo who has given the permission for doctoral study. Thanks to the promoter, co-promoter 1, and co-promoter 2 who have guided in carrying out the research. The researcher also expressed his gratitude to the Tundang Mayang Pusaka studio leads by Eddy Ibrahim in Mempawah west Borneo for giving permission in conducting the research 


\section{REFERENCES}

[1] I. M. Astika and I. N. Yasa, Sastra Lisan: Teori dan Penerapannya. Yogyakarta: Graha Ilmu, 2014.

[2] J. H. Brunvand, American Folklore An Encyclopedia. New York: Garland Publishing, 1996.

[3] J. Danandjaja, Folklor Indonesia Ilmu Gosip, Dongeng, dan Lain-lain. Jakarta: Grafiti, 2002.

[4] R. Finnegan, Oral Tradition and The Verbal Arts. A Guide to Research Practices. London: Routledge, 1992.

[5] G. Kress and T. Van Leeuwen, Multimodal Discourse: The Modes and Media Of Contemporary Communication. London: Arnold, 2001.

[6] G. Kress and T. Van Leeuwen, "Analysis of Newspaper," in Approaches to Media Discourse, A. Bell and P. Garret, Eds. Oxford: Blackwell, 1996.

[7] R. Iedema, "Multimodality, resemiotization: extending the analysis of discourse as multi-semiotic practice," Vis. Commun., vol. 2, no. 1, pp. 29-57, Feb. 2003.

[8] Yumin Chen, "Exploring dialogic engagement with readers in multimodal EFL textbooks in China," Vis. Commun., vol. 9, no. 4, pp. 485-506, Nov. 2010.

[9] T. S. Sinar, Teori \& Analisis Wacana Pendekatan Linguistik Sistemik Fungsional. Medan: Mitra, 2012.

[10] M. Anstey and G. Bull, "Helping Teacher To Explore Multimodal Texts," An Electron. J. leaders Educ., vol. 8, no. 16, 2010.

[11] M. A. K. Halliday, An Intoduction To Functional Grammar. New York: Oxford University Press Inc, 2004. 